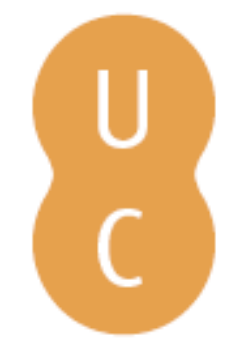

\title{
pompalina
}

\section{Adornos anulares en la Antigüedad Tardía: criterios para la catalogación de la colección del Museo Nacional de Arte Romano de Mérida (Badajoz, España)}

Autor(es): $\quad$ Barrero Martín, Nova

Publicado por: Imprensa da Universidade de Coimbra

URL

persistente: URI:http://hdl.handle.net/10316.2/42113

DOI: $\quad$ DOI:https://doi.org/10.14195/978-989-26-1353-6_7

Accessed : $\quad$ 26-Apr-2023 15:28:40

A navegação consulta e descarregamento dos títulos inseridos nas Bibliotecas Digitais UC Digitalis, UC Pombalina e UC Impactum, pressupõem a aceitação plena e sem reservas dos Termos e Condições de Uso destas Bibliotecas Digitais, disponíveis em https://digitalis.uc.pt/pt-pt/termos.

Conforme exposto nos referidos Termos e Condições de Uso, o descarregamento de títulos de acesso restrito requer uma licença válida de autorização devendo o utilizador aceder ao(s) documento(s) a partir de um endereço de IP da instituição detentora da supramencionada licença.

Ao utilizador é apenas permitido o descarregamento para uso pessoal, pelo que o emprego do(s) título(s) descarregado(s) para outro fim, designadamente comercial, carece de autorização do respetivo autor ou editor da obra.

Na medida em que todas as obras da UC Digitalis se encontram protegidas pelo Código do Direito de Autor e Direitos Conexos e demais legislação aplicável, toda a cópia, parcial ou total, deste documento, nos casos em que é legalmente admitida, deverá conter ou fazer-se acompanhar por este aviso.

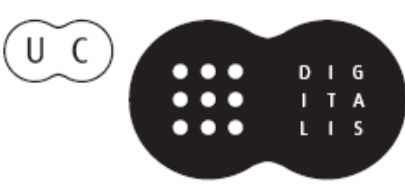




\section{Arqueologia \\ da transição:}

entre o mundo romano

e a Idade Média

Cláudia Teixeira, André Carneiro (coords.)

IMPRENSA DA UNIVERSIDADE DE COIMBRA

ANNABLUME 


\title{
Adornos anulares en la Antigüedad Tardía: Criterios para la catalogación de la colección del Museo Nacional de Arte Romano de MÉrida (Badajoz, España) (Annular adornments in Late Antiquity: cataloguing criteria for the collection in Museo Nacional de Arte Romano de Mérida (Badajoz/España))
}

\author{
Nova Barrero Martín (nova.barrero@mecd.es) \\ Museo Nacional de Arte Romano de Mérida
}

\begin{abstract}
Resumo - Neste estudo pretendemos analisar os adornos pessoais da Antiguidade Tardia que pertencem às reservas do Museo Nacional de Arte Romano, e em específico, os ornamentos anelares. Representam a importância que a cidade de Augusta Emerita deteve, bem visível no domínio da cultura material e, em específico, da torêutica deste período. A análise sistemática da colecção do Museu e a aplicação de critérios de catalogação que não são exclusivamente tipológicos trouxe avanços para a investigação e estudo destes 26 anéis, muitos dos quais ainda inéditos, e que este estudo preliminar permite divulgar.

Palavras-chave - Museo Nacional de Arte Romano em Mérida; Augusta Emerita; Antiguidade Tardia; adornos pessoais; anéis
\end{abstract}

АвsTRACт - In this research, we release the personal ornaments assemblage belonging to late antiquity from the National Museum of Roman Art, annular ornaments specifically. It is significant how the importance of the antique city Augusta Emerita is not return to material culture and to collection of Toreutica specifically in this period. The systematic analysis of the Museum's collection and the application of cataloguing criteria not typological exclusively, have yielded positive results. We show 26 rings in the aggregate, many unpublished, in this preliminary study.

Keywords - National Museum of Roman Art in Mérida, Augusta Emerita, Late Antiquity, personal ornaments, rings

Una de los interrogantes de la arqueología emeritense referente a la Antigüedad Tardía es la mínima representación de adornos personales correspondientes a este período, al menos la bibliografía así lo reflejaba, lo que se contradice con la amplia documentación histórico, literaria y arqueológica que existe para la Augusta Emerita tardoantigua (Álvarez Martínez y Mateos Cruz 2011) ${ }^{1}$. Por ello, establecer patrones y criterios de catalogación definidos, que permitieran revisar la colección del Museo Nacional de Arte Romano de Mérida (en ade-

${ }^{1}$ Las Actas del Congreso Internacional 1910-2010. El yacimiento Emeritense es una buena muestra del actual conocimiento de la Augusta Emerita en la Antigüedad Tardía. 
lante MNAR) con un nuevo enfoque y perspectiva, fue el planteamiento de este trabajo, incluido en el estudio mucho más amplio ${ }^{2}$, siendo conscientes de que quizá sea también unos de los aspectos más controvertidos.

Por un lado, hay que tener presente la ausencia de documentación sobre la procedencia y/o contexto arqueológico de buena parte de la colección de adornos personales del MNAR, que entraron a formar parte de las colecciones como "Fondo Antiguo". Por otra parte, desde una perspectiva tradicional, el empleo de un único criterio de estudio, como era el tipológico, para estos materiales, con la ausencia de fósiles directores, concluyó con la práctica ausencia de estudios específicos sobre toréutica tardoantigua en Augusta Emerita. Una nueva visión más amplia de lo que supone la cultura material de estos siglos, así como los últimos hallazgos a cargo del Consorcio de la Ciudad Monumental de Mérida, permite hablar ya de un catálogo de materiales (Pérez Maestro 2005; Heras Mora 2006; Cantillo Vázquez 2007).

La revisión sistemática de la colección de adornos personales del MNAR, la aplicación de nuevos criterios para su catalogación, especialmente para el caso de los adornos anulares, permite poner a discusión en este trabajo un buen número de piezas que nos informan sobre el uso de este tipo de objetos en el territorio de Augusta Emerita en la Antigüedad Tardía.

\section{Catálogo de materiales}

En la revisión y estudio de la colección de anillos del MNAR, la determinación de su adscripción cronocultural a la Antigüedad Tardía viene dada fundamentalmente por el empleo de dos criterios en su catalogación:

- Contexto Arqueológico: La ampliación de este criterio prima sobre cualquier otro. Todos los adornos anulares procedentes de excavaciones cuyo contexto arqueológico nos sitúe en el ámbito de estudio, están incluidos.

- Epigráfico/Iconográfico: La presencia de monogramas y/o advocaciones cristianas que atestiguan la fe de su poseedor, o símbolos iconográficos más complejos que tienen el mismo objetivo, sin duda nos sitúa en un momento cronológico, al menos, post quem a la llegada del cristianismo y, por tanto, cronológicamente dentro del período de estudio de este trabajo.

${ }^{2}$ Desde el Departamento de Investigación del MNAR y dentro del Grupo Regional de Investigación (EMA-HUM 016) desarrollamos una línea de trabajo referente a la Toréutica de la Antigüedad Tardía en la Lusitania. En 2011 presentamos el Trabajo de Fin de Máster bajo el título La colección de Toréutica Cristiana del Museo Nacional de Arte Romano de Mérida en la Antigüedad Tardía y en Época Visigoda (siglos IV-VII d.C.). 
Por otro lado, hay que subrayar que un criterio de catalogación no empleado ha sido el tipológico. Mientras que la aplicación del mismo para otros grupos de piezas que han sido objeto de estudios monográficos extensos, como por ejemplo, los broches de cinturón, han dado de fructíferos resultados en el caso hispano (Ripoll López 1998), en el caso de los adornos anulares no existen tales estudios de referencia.

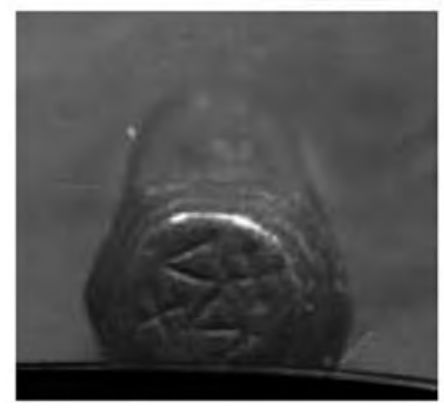

N. 01 - Lám. I, Fig. 1 (Inv. CE00222).

Bronce. Fundido y cincelado. Diámetro: $24 \mathrm{~mm}$. Inscripción: (Cruz) VM (Cruz) o VIVA. Datación: Siglo VI-VII d. C.

Comentario: Anillo de chatón hexagonal, en el que aparecen inscritas dos letras en el centro, reconocidas como "V" y "M", que comparten uno de los brazos de las letras. En la parte superior e inferior, dos cruces. La pieza ingresa en el Museo antes de 1910. Actualmente se encuentra en paradero desconocido y sólo se conocía por referencias antiguas, hasta que gracias a un proyecto actual del MNAR de digitalización del Archivo Fotográfico permitió rescatar una placa de vidrio que, aunque fragmentada, permite reconocer y estudiar la pieza.

La pieza recoge una tipología típica de los anillos visigodos, realizada en bronce y con modelo de chatón, para albergar signos cristológicos junto a inscripciones (Reinhart 1947: 168.). De acuerdo a la lectura realizada por Ramírez Sádaba, que no pudo consultar la pieza por estar desaparecida, se trataría del típico modelo en el que se recoge el monograma, posiblemente del poseedor de la pieza, un individuo masculino a juzgar por el diámetro, en el que éste es acompañado de los símbolos propios de la religión que profesa, como son las cruces que delimitan al mismo.

Otra opción posible de lectura sería "VIVA", advocatoria resumida de "Vivas in Deo" o "Vivas in Christo", presente en distintos objetos así como en encabezamientos de epitafios (González Fernández 2002). Su presencia en anillos también es relativamente usual, bien con advocatoria completa, como es el caso del anillo de Baena (no Inv. 10/3/1) (Morena y Sánchez 2011) o como parece presentarse en el anillo hallado en la Sepultura no 34000-12 de 
la necrópolis oriental de Cartagena (CA4-34356-902-1) (Madrid Balanza y Vizcaíno Sánchez 2006: 113-114, Fig 6.3.), o bien en expresión reducida, tal y como puede observarse en algunos anillos visigodos procedentes de Sierra Elvira, publicados por Gómez Moreno (Gómez Moreno 1888, n 253, 254 y 255, Lám.XVII) y posteriormente recogidos por Reinhart. Concretamente el n. ${ }^{\circ} 65$ del catálogo del autor alemán recoge un esquema epigráfico similar (Reinhart 1947: 76, n. ${ }^{\circ} 65$ ) al ejemplo emeritense. Sería, por tanto, otra opción posible y muy sugerente.

Bibliografía: RAMÍREZ SÁDABA, J.L. y MATEOS CRUZ, P. 2000, no 173, p. 216-217; NAVASCUÉS, J. M. 1948, n.o 70, p. 271.

\section{N. 02 - (Inv. CE00223)}

Bronce. Fundido y cincelado. Diámetro: 29 mm. Peso: 1,13 g. Datación: Siglo VI-VII d. C.

Comentario: Aro laminiforme. Sus extremos se superponen para cerrarse y sufre un ligero ensanchamiento en el centro para formar chatón, en el que se graba una cruz.

La pieza pertenece a una de las tipos morfológicos más sencillos de los anillos, con una configuración y un método de fabricación simple. Sin embargo, si no fuera por el símbolo que presenta en el chatón sería muy difícil una adscripción plausible al período cristiano.

Esta forma de fabricación, una lámina que cierra superponiendo los dos extremos, tuvo gran difusión en la Antigüedad Tardía, usando el chatón para la plasmación de inscripciones o símbolos cristianos, como en este caso. El uso de este sistema de cierre permitiría la adaptación al usuario y es bastante común en necrópolis visigodas, con numerosos paralelos como los procedentes de la necrópolis de Pamplona (Mezquiriz Irujo 1965: 55, Lám. XI.13).

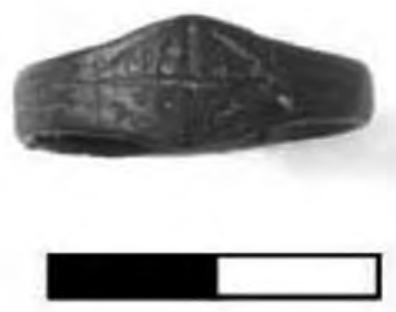

N.o 3 - Lám. I, Fig. 2 (Inv. CE11277).

Bronce. Fundido y cincelado. Diámetro: 22 mm. Peso: 2,45 g. Datación: Siglo VI-VII d. C.

Comentario: Aro compuesto por lámina de sección semicircular, que se solapa en los extremos para cerrarse y se ensancha en el centro para recibir decoración. Ésta se compone de cruz inscrita en lonsange y agrupaciones de puntos de dos, 
cuatro, dos y tres (leídos de izquierda a derecha y de arriba a bajo) en los espacios en hueco. El campo se cierra con dos líneas horizontales, seguidas por dos líneas verticales paralelas que corren a lo largo del aro, cerradas en uno de los lados por otra línea horizontal.

La cruz como motivo único es de uso habitual en los anillos cristianos y también, como en este caso incluida, en lonsange. Ejemplos similares son recogidos por Reinhart (Reinhart 1947: 168).
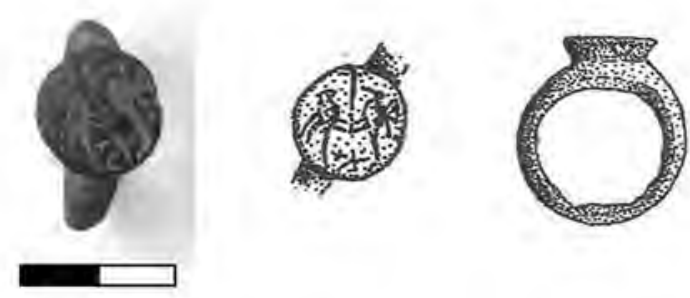

N. 4 - Lám. I, FigG. 3 (Inv. CE11278).

Bronce. Fundido y cincelado. Diámetro: $27 \mathrm{~mm}$. Peso: 14,82 g. Datación: Siglo IV-VII d.C.

Comentario: Aro de sección semicircular, plano al interior. Presenta chatón circular, con imagen grabada de dos aves de cola larga afrontadas en torno a un vástago central y estrella en la parte inferior.

La tipología de anillo, aro con chatón circular, es de larga tradición romana y no presenta una novedad en los objetos de adorno personal. Sin embargo, el tipo decorativo recogido en el chatón es el que lo introduce en los tipos iconográficos del mundo cristiano. Efectivamente, la imagen de dos aves afrontadas en torno a un elemento central (rueda calada, crismón, cratera, vaso.. etc) es habitual en el repertorio decorativo cristiano a partir del siglo iv d.C., primero con una carga simbólica muy significativa y, avanzado el tiempo, como motivo meramente ornamental. En este caso las aves representadas son pavos reales, ya que la larga cola permite su identificación. El Pavo Real, espacialmente en contextos funerarios, parece aludir a la resurrección cristiana. Los pavos afrontados serían un trasunto del tema pagano, ya reconvertido a la moral cristina, según el cual existe la leyenda de que su carne es incorruptible por su asociación al mito del Ave Fénix y, por tanto, inmortal, igual que el alma cristiana (Bisconte 2000: 111).

Conocemos un paralelo exacto al anillo emeritense, procedente de un área funeraria visigoda cordobesa y conservado actualmente en el Museo Arqueológico de la ciudad (N.o inv. CE027841) ${ }^{3}$. Aunque la tipología de anillo varía, ya que en

\footnotetext{
${ }^{3}$ Ficha de Inventario del Museo Arqueológico de Córdoba.
} 
este caso se trata de un aro que se ensancha en el centro de forma circular, para formar chatón, el tipo decorativo que presenta es muy semejante. Se trata de dos aves afrontadas en torno a una cruz, formada por cuatro triángulos dispuestos radialmente. Toda la escena está enmarcada por una grafila de puntos. El contexto del hallazgo está fechado entre el siglo v y viı d.C.

Reinhart, en su estudio de los anillos hispanovisigodos, recoge también un ejemplar de características muy similares. Se trata de un anillo procedente de Sierra Elvira, conformado por aro y chatón circular, con dos aviformes enfrentadas en torno a un vástago central, rematado en cruz (Reinhart 1947: 177, Fig. 3.55). Se trataría, según Reinhart, de un tipo iconográfico bizantino y el anillo, un producto de importación.

Sólo a modo de ejemplo, citaremos algunas piezas de la espléndida colección de escultura visigoda emeritense que presentan este mismo esquema iconográfico: un friso decorativo (Inv. CE 08.219) (Cruz Villalón 1985: 136, n. ${ }^{\circ}$ 354), que posiblemente formaría parte de un monumento funerario, y la placa que hoy conserva el MAN (Inv. CE07763) (Cruz Villalón 1985: 148, n.o 406). Además, el trasunto del tema tiene su plasmación en otras piezas de gran interés, en la que los pavones son sustituidos por aves identificadas con palomas, enfrentadas en torno a un vaso. Se trata de una placa-nicho (Inv. CE08565) (Cruz Villalón 1985: 82, n. $\left.{ }^{\circ} 135\right)$, pieza de gran importancia en el programa iconográfico por la situación preponderante que guardaría en la decoración de los edificios religiosos este tipo de piezas.
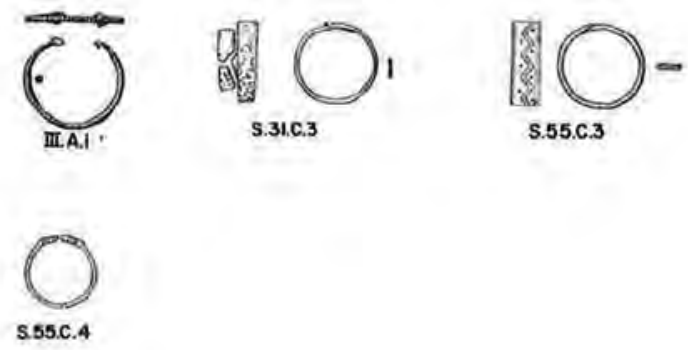

S.55.c.3

N. o 5- Lám. I, Fig. 4 (según CABALLERO y ULBERT) (Inv. CE11977).

Bronce. Fundido y cincelado. Diámetro: $21 \mathrm{~mm}$. Peso: 65 g. Procedencia: Mérida. Basílica de Casa Herrera. Nave central. Datación: Siglo VI-VII d. C

Comentario: Aro filiforme de sección circular, decorado con estrías, fragmentado en el centro, donde ha perdido el chatón.

El anillo fue hallado en la Nave Central de la Basílica de Casa Herrera, durante la campaña de 1968. La tipología de anillos con chatón para engastar piedras o vidrios es común en las necrópolis de la Antigüedad Tardía, y son claros ejemplos de la perduración de modelos romanos en este período. Es habitual, en este tipo de anillos, que sea el chatón el elemento perdido, al ser la unión con el 
aro el elemento más débil y el chatón la pieza más sobresaliente. Sólo el contexto arqueológico permite datar estos objetos, ya que no existen diferencias entre los fabricados en época romana y los de momentos posteriores.

Bibliografía: CABALLERO, L. y ULBERT, T. 1976: 113, Fig. 19. II.A.1.
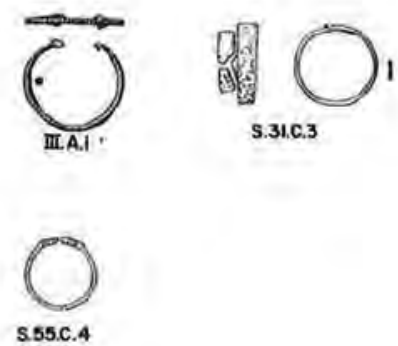

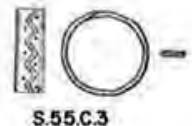

S.55.C.3

N. 6 - Lám. I, Fig. 4 (según CABALLERO y ULBERT) (Inv. CE12008).

Bronce. Fundido. Diámetro: $15 \mathrm{~mm}$. Peso: 0,79 g. Procedencia: Mérida. Basílica de Casa Herrera Sepultura 19, estrato II. Datación: Siglo VI-VII d. C.

Comentario: Aro laminar, cuyos extremos se superponen para cerrarse. En la zona central presenta cierto ensanchamiento. El borde del aro aparece decorado con sendas gráfilas de puntos, mientras que el centro está ocupado por una línea continua en ziczac. La decoración está muy perdida.

La pieza se halló dentro de la Sepultura 19 de Casa Herrera. Parece que formaría parte del ajuar de un individuo, cuyos restos habían sido arrinconados dentro de la tumba, para que ésta pudiera ser reaprovechada.

Nos encontramos de nuevo ante una tipología sencilla de adorno anular, en este caso dignificada por la decoración grabada que presenta. Ésta no es inusual. En la propia Basílica se halló otro anillo de semejante decoración, incluido en este estudio (n. ${ }^{\circ}$ ).

Bibliografía: CABALLERO, L. y ULBERT, T. 1976: 154, Fig. 41.S.19.C.4.

N.o 7 - (Inv. CE16462)

Bronce. Fundido y cincelado. Diámetro: $18 \mathrm{~mm}$. Gr. $2 \mathrm{~mm}$. Peso: 0,74 g. Procedencia: Mérida. Basílica de Casa Herrera. Sepultura n. ${ }^{\circ} 55$. Datación: Siglo VI-VII d. C.

Comentario: Aro laminar, cerrado por la yuxtaposición de sus extremos. Presenta decoración incisa de doble línea de zigzag y triángulos en los espacios libres que forman. Una cenefa de pequeñas líneas paralelas define el perímetro de toda la pieza.

$\mathrm{El}$ anillo apareció, junto al n. ${ }^{\circ} 8$ de este catálogo, en la Sepultura 55, dentro de la necrópolis extendida en los alrededores de la Basílica, durante la campaña de 1972. El individuo era una mujer de edad madura. El ajuar se completaba con dos jarros típicamente visigodos. 
El tipo de anillo pertenece de nuevo a lámina doblada sobre sí misma para amoldarse el dedo del usuario y cerrarse, ya comentada. La decoración en ziczac con puntos en los intersticios es un motivo de antiquísimas raíces mediterráneas, que en el mundo tardoantiguo y visigodo adquiere un especial protagonismo en los objetos de adorno personal.

Bibliografía: CABALLERO, L. y ULBERT, T. 1976: 182, Fig. 57.S.55.C.3.
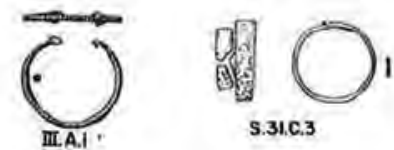

S.31.C.3

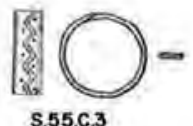

S.55.C.3

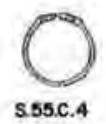

N.o 8 - Lám. I, Fig. 4 (según CABALLERO y ULBERT) (Inv. CE16463).

Bronce. Fundido y cincelado.: Diámetro: $17 \mathrm{~mm}$. Anch. $1 \mathrm{~mm}$. Gr. $1 \mathrm{~mm}$. Peso: 0,47 g. Procedencia: Mérida. Basílica de Casa Herrera. Sepultura n.o 55. Datación: Siglo VI-VII d. C.

Comentario: Aro filiforme, conformado por hilo de bronce de sección circular, con extremos decorados mediante otro hilo enrollado sobre estos. Está roto en esta zona decorada.

$\mathrm{El}$ anillo apareció junto al anillo n. 7 de este trabajo. De nuevo nos encontramos ante un método de fabricación sencilla, aunque muy resolutiva: hilo de bronce que se retuerce y se dobla sobre sí mismo para cerrarse.

Bibliografía: CABALLERO, L. y ULBERT, T. 1976 182, Fig. 57.S.55.C.4.
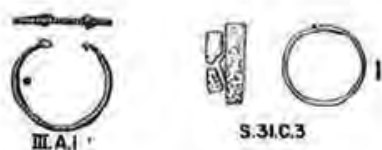

S.31.C.3

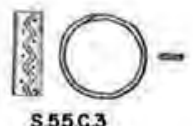

S.55.C.3

N. 9 - Lám. I, Fig. 4 (según CABALLERO y ULBERT) (Inv. CE16464).

Bronce. Fundido y cincelado. Diámetro: $18 \mathrm{~mm}$. Anch. $4 \mathrm{~mm}$. Gr. $2 \mathrm{~mm}$. Peso: 1,05 g. Procedencia: Mérida. Basílica de Casa Herrera. Sepultura n. 31. Datación: Siglo VI-VII d. C. 
Comentario: Aro laminar, de sección plana, cerrado por la yuxtaposición de sus extremos. El anillo apareció en la Sepultura 31 de la Basílica de Casa Herrera (Mérida), en la campaña de 1972, en la mano izquierda del esqueleto hallado en su interior. Éste pertenecía a un cuerpo femenino maduro. El ajuar se completaba con otro anillo de hierro, unido a éste, hoy perdido, así como un jarro y una olla típicamente visigodos.

Bibliografía: CABALLERO, L. y ULBERT, T. 1976: 166, Fig. 47.S.31.C.3.

\section{N. ${ }^{\circ} 10$ - (Inv. CE16465).}

Bronce. Fundido y cincelado. Diámetro: 23 mm. Anch. 3 mm. Gr. 3 mm. Peso: 2,98 g. Procedencia: Mérida. Basílica de Casa Herrera. Nave Lateral Sur. Datación: Siglo VI-VII d. C.

Comentario: Aro de sección circular. Presenta concreciones por oxidación. El anillo fue hallado en la Nave Lateral Sur de la Basílica durante las labores de limpieza de la campaña de 1972. Destaca su extrema sencillez.

Bibliografía: CABALLERO, L. y ULBERT, T. 1976: 166, Fig. 47.S.31.C.3.

\section{N.o 11 - (Inv. CE16494).}

Bronce. Fundido y cincelado. Diámetro: $21 \mathrm{~mm}$. Anch. $7 \mathrm{~mm}$. Gr. $3 \mathrm{~mm}$. Peso: 3,12 g. Procedencia: Mérida. Basílica de Casa Herrera. Habitación NO interior. Datación: Siglo VI-VII d. C.

Comentario: Aro de sección semicircular, plano al interior, que se ensancha en el centro para formar chatón. Parece que hubo elementos grabados en éste, pero no se conservan.

El anillo fue hallado en la Habitación NO interior de la Basílica, durante las labores de limpieza de la campaña de 1972.

Su morfología es bien conocida dentro de las tipologías de anillos tardoantiguos: fabricado en lámina de bronce, que se ensancha para formar chatón; en éste se incluía el nombre del propietario o signos de adscripción cristiana del mismo. Sin embargo, en este caso sólo se observan restos de algún grabado indescifrable.

Bibliografía: CABALLERO, L. y ULBERT, T. 1976: 166, Fig. 47.S.31.C.3.

\section{N.o 12 - Lám. I, Fig. 5 (Inv. CE17818).}

Bronce. Fundido y cincelado. Diámetro: $20 \mathrm{~mm}$. Peso: 2,5 g. Procedencia: Mérida. Teatro romano. Ingresa el 3/7/73. Inscripción: (Cruz) EMILIA. Datación: Siglo VI-VII d. C

Comentario: Aro de sección semicircular que se ensancha en el centro para recoger la inscripción. Ésta está antecedida por una cruz griega de brazos patados. La inscripción reza un nombre femenino, Emilia.

Nos encontramos ante un ejemplar que sigue modelos habituales en el artesanado visigodo, con la singularidad de que en este caso el chatón no recoge un monograma sino el nombre completo de la dueña y usuaria del 
anillo, que reafirma a su vez su condición cristiana con la inclusión de cruz antecediendo el nombre.
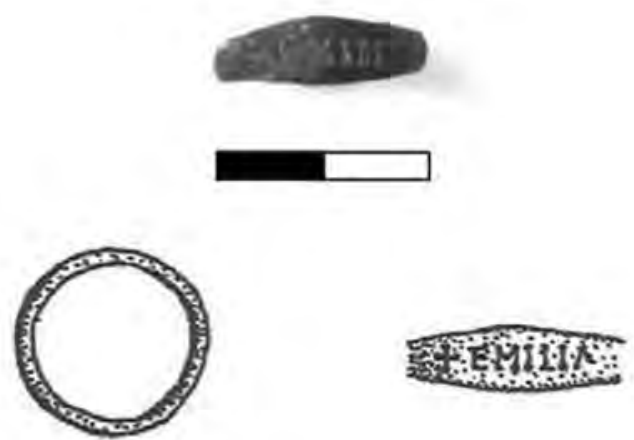

Conocemos algún ejemplar procedente de la propia Mérida que sigue este mismo modelo de incluir el nombre completo del propietario en el adorno anular del chatón. Es el caso del no 18 de este trabajo, con el nombre de Iusta, o la posibilidad de que los no $1,17,21$ y 22 , cuya inscripción no ha podido ser leída correctamente, también incluyan el nombre, o funcionaran como anillos signatarios.

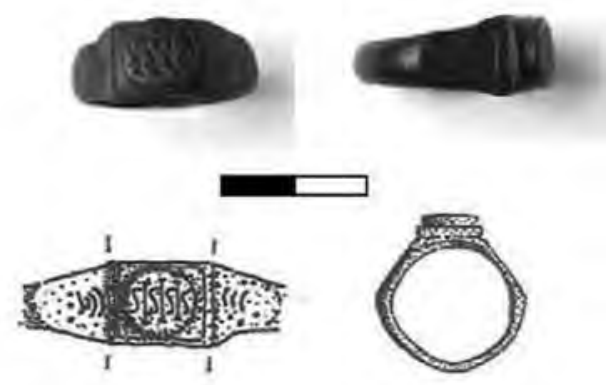

N. 13 - Lám. I, Fig. 6 (Inv. CE19333).

Bronce. Fundido y cincelado. Diámetro: $25 \mathrm{~mm}$. Peso: 9,55 g. Procedencia: Mérida. Donación. Casa del Anfiteatro. Ingresado el 14/01/1974. Inscripción: SISISIS. Datación: Siglo VI-VII d. C.

Comentario: Aro de sección semicircular y aplanado y recto en las laterales al chatón. Éste es rectangular de doble moldura, sobre el que se dispone otra moldura circular que recibe la inscripción de cuatro "S" separadas por tres vástagos rematados por triángulos en sus extremos. En los laterales al chatón, incisas tres medias lunas y serie de tres puntos.

$\mathrm{El}$ adorno anular procedente de la Casa del Anfiteatro alberga en su chatón cuadrangular un motivo usado típicamente en la metalistería visigoda, aunque no es propia de ella. El motivo puede ser identificado o asemejado a los estrigiles, que ya tuvieran gran éxito en los sarcófagos paleocristianos enmarcando las escenas principales de los lados mayores y que para este tipo de piezas se usan como 
motivos decorativos en anillos y otros objetos de adorno personal. Así es reconocido por Reinhart, que recoge un anillo con tema decorativo similar (Reinhart 1947: 177, Fig. 3.50).

Además, se conocen otros anillos visigodos con tema de estrígiles, separados en ocasiones por elementos verticales, como es el caso del emeritense. Por su mayor cercanía citaremos, en primer lugar, el anillo hallado en la necrópolis visigoda de El Caballar (Usagre, Badajoz) (Ortiz Alesón y Blasco Rodriguez 1985: 165-166, Fig. 2, Lám. I, 1 y 2), que fue hallado con laminilla de plata enrollado sobre el aro, lo que hace suponer a los arqueólogos que se portaría colgado y empleado, cuando se necesitase, como anillo signatario. Otro ejemplo es el procedente de la necrópolis de Durantón y publicado por Molinero Pérez (Molinero Pérez 1971, Lám. XLIV, sep. 498, n. ${ }^{\circ} 884$ ). También Zeiss recoge en su estudio monográfico un anillo con esquema decorativo similar (Zeiss 1934, Lám. 25.2).

Otos objetos propios de la metalistería visigoda emplearon motivo idéntico en su decoración. Algunos ejemplos serían el hebijón de la hebilla hallada en la tumba 34 AT de la necrópolis de El Ruedo (Almedinilla-Córdoba) (Muñiz Jaén y Bravo Carrasco 2000: 193), datado en el siglo VI d.C., o la hebilla y base de la aguja de un broche conservado completo, procedente de la sepultura 31 de la necrópolis de Herrera del Pisuerga (Martínez Santa Olalla 1933: 42, Lám. L).

Bibliografía: RAMÍREZ SÁDABA, J. L. y MATEOS CRUZ, P. 2000, n. ${ }^{\circ}$ 174, p. 217; NAVASCUÉS, J. M. 1948, n. ${ }^{\circ}$ 72, p. 274.

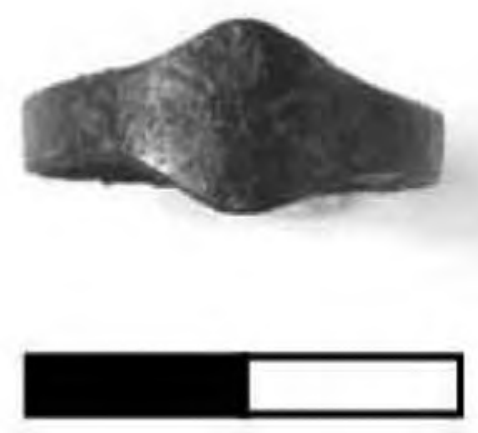

N.o 14 - Lám. II, Fig. 1 (Inv. CE29231).

Bronce. Fundido y cincelado. Diámetro: 19 mm. Peso: 1,64 g. Datación: Siglo VI-VII d. C.

Comentario: Aro conformado por lámina plana, que en los extremos se superpone para cerrarse. En el centro de ensancha de forma romboidal, donde tiene incisa una cruceta.

La tipología simple de anillo, laminar con ensanchamiento para la constitución de chatón, y el sistema de cierre son elementos ya observados en otros ejemplares recogidos en este estudio. Como motivo decorativo, una simple cruceta adaptada a la forma en lonsange del chatón, que tuvo gran aceptación en la 
metalistería visigoda a juzgar por numerosos ejemplos conocidos y de los que recogemos algunos paralelos con los conocidos de la necrópolis de Pamplona (Mézquiriz 1965, Lám.X, n. ${ }^{\circ} 10$ y 11), la tumba n.o 51 de de Herrera del Pisuerga (Martínez Santa Olalla 1933: 44, Lám. LV.) o ejemplares procedentes de la zona salmantina (Morín de Pablos y Barroso Cabrera 2010: 170, Fig. 20, n. ${ }^{\circ}$ 12).

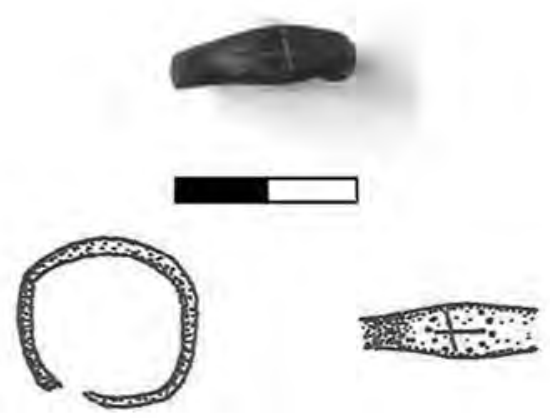

N. $15-$ Lám. II, Fig. 2 (Inv. CE29403).

Bronce. Fundido y cincelado. Diámetro: $21 \mathrm{~mm}$. Peso: 1,94 g. Datación: Siglo VI-VII d. C.

Comentario: Aro laminar, roto en uno de los extremos. Se ensancha en el centro para dar lugar al chatón, decorado con cruz latina rodeada de puntos.

El ejemplar repite modelos simplificados, bien conocidos dentro del contexto de estudio. La simplificación del motivo decorativo en el chatón, la cruz, en este caso rodeada de puntos, ha sido analizada ya, al igual que el sistema de cierre, que en este caso volvería a repetir el solapamiento de los extremos y su ajuste por presión al usuario.
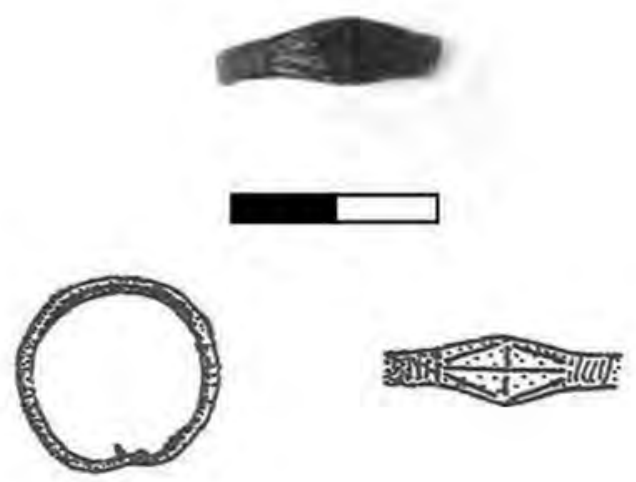

N. 16 - Lám. II, Fig. 3 (Inv.CE29407).

Bronce. Fundido y cincelado. Diámetro: 22 mm. Peso: 1,66 g. Datación: Siglo VI-VII d. C. 
Comentario: Aro compuesto por lámina de sección semicircular, que en los extremos se superpone para cerrarse. En el centro se ensancha para recibir decoración. Ésta se compone de cruz inscrita en lonsange, cercada en los laterales por tres líneas paralelas.

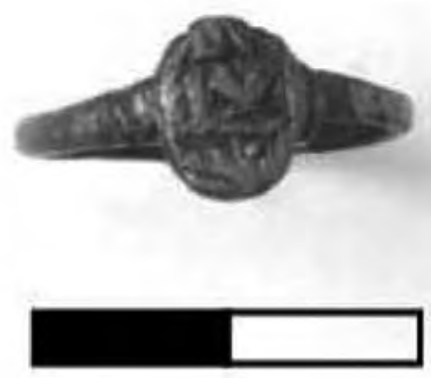

N. 17 - Lám. II, Fig. 4 (Inv. CE29408).

Bronce. Fundido y cincelado. Diámetro: $21 \mathrm{~mm}$. Peso: 1,44 g. Inscripción: D (.) / LV / (.) V (.). Datación: Siglo VI-VII d. C.

Comentario: Aro filiforme de sección semicircular que lleva soldado el chatón de forma elipsoide. Éste contiene inscripción en tres registros, que se conserva muy desgastada en los laterales.

El ejemplar sigue modelos de tradición romana que perduraron durante Antigüedad Tardía, con chatón para la inclusión de nombres o monogramas, funcionando o no como anillos signatarios. En este caso el nombre no ha podido ser leído, debido al desgaste sufrido por el uso. A la dificultad de leerlo de forma fiel, se une el hecho de que estos monogramas son en muchas ocasiones indescifrables.

Bibliografía: RAMÍREZ SÂDABA, J. L. y MATEOS CRUZ, P. 2000, n. ${ }^{\circ}$ 172, p. 216; NAVASCUÉS, J. M. 1948, n. ${ }^{\circ}$ 69, p. 270.

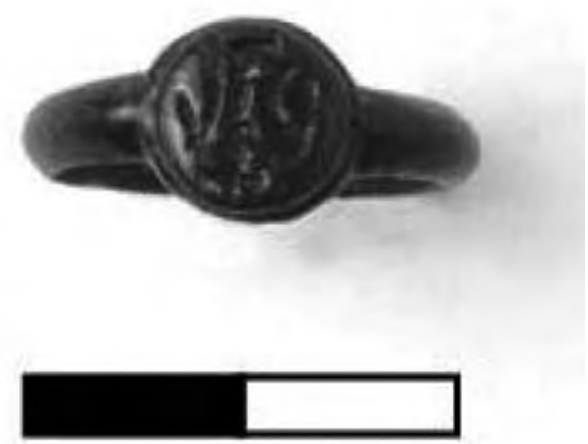

N. o 18- Lám. II, Fig. 5 (Inv. CE29449).

Bronce. Fundido y cincelado. Diámetro: $21 \mathrm{~mm}$. Peso: 3,59 g. Inscripción: (Cruz) IUSTA. Datación: Siglo VI-VII d. C. 
Comentario: Aro de sección semicircular con chatón circular de doble moldura. Inscrito en él, nombre femenino, Iusta, en el que se enlazan las tres primeras letras. El nombre queda enmarcado por dos pequeñas líneas horizontales. Bajo la superior una cruz griega.

Una vez más, el chatón sirve para identificar al dueño y portador de la pieza, en este caso un individuo femenino, Iusta, que además reafirma su fe con la inclusión de una cruz sobre el nombre.

Bibliografía: RAMÍREZ SÁDABA, J. L. y MATEOS CRUZ, P. 2000, n. ${ }^{\circ}$ 167, p. 213; VIVES, ICERV: 1969, n.o 394; NAVASCUÉS, J. M. 1948, n. ${ }^{\circ}$ 71, p. 272-73; MÉLIDA, J. R. 1925, Tomo II, n. ${ }^{\circ} 2115$.
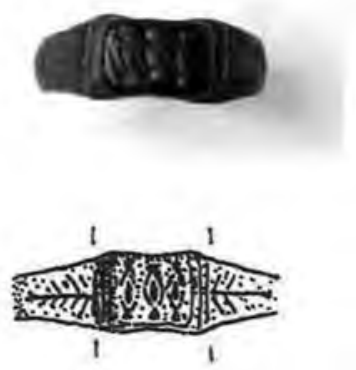
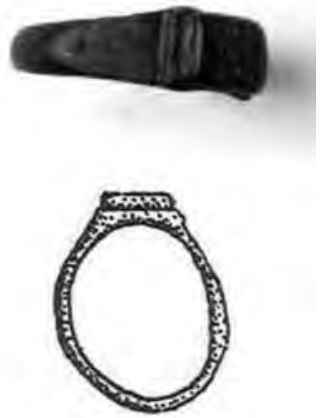

N.o 19- Lám. II, Fig. 6 (Inv. CE32525).

Bronce. Fundido y cincelado. Diámetro: $24 \mathrm{~mm}$. Peso: 4,51 g. Datación: Siglo VI-VII d. C.

Comentario: Aro se sección semicircular, que se aplana en los laterales del chatón. Éste es de morfología cuadrangular, en doble moldura, con decoración de tres elipses, enmarcadas por cuatro rayitas cada una y rematadas en los extremos por triángulos. Tanto estos últimos como las elipses conservan restos de la pasta de color claro decorativa que iría incrustada. En los laterales del chatón, aplanados, se observan sendas palmas.

El motivo iconográfico empleado es conocido en otras piezas correspondientes a la toréutica tardoantigua halladas en contexto, que permiten la adscripción temporal de la pieza emeritense. El problema estriba en su correcta interpretación o identificación con motivos propios de la iconografía tardoantigua, lo cual no ha podido ser realizada hasta estos momentos. La palmeta por su parte, que aparece como elemento complementario en los laterales al chatón, sí es motivo bien conocido en la plástica cristiana, como símbolo de victoria y triunfo.

Entre los paralelos conocidos de esta pieza cabe citar el ejemplar recogido por Gómez Moreno de Sierra Elvira y dibujado por él (Gómez Moreno 1888, Lám. XVII, n. ${ }^{\circ}$ 259), e incluido por Reinhart en su estudio (Reinhart 1947: 76, Fig. 3, n. ${ }^{\circ}$ 68), la pieza recogida por Morín de Pablos y Barroso Cabrera 
procedente de la zona salmantina y que repite las palmas en los laterales del chatón (Morín de Pablos y Barroso Cabrera 2010: 170, Fig. 20.H) o el ejemplar hallado en la sepultura no 345 de Madrona (Segovia) (Molinero Pérez, A. 1971, Lám. XCIV, Fig. 1).
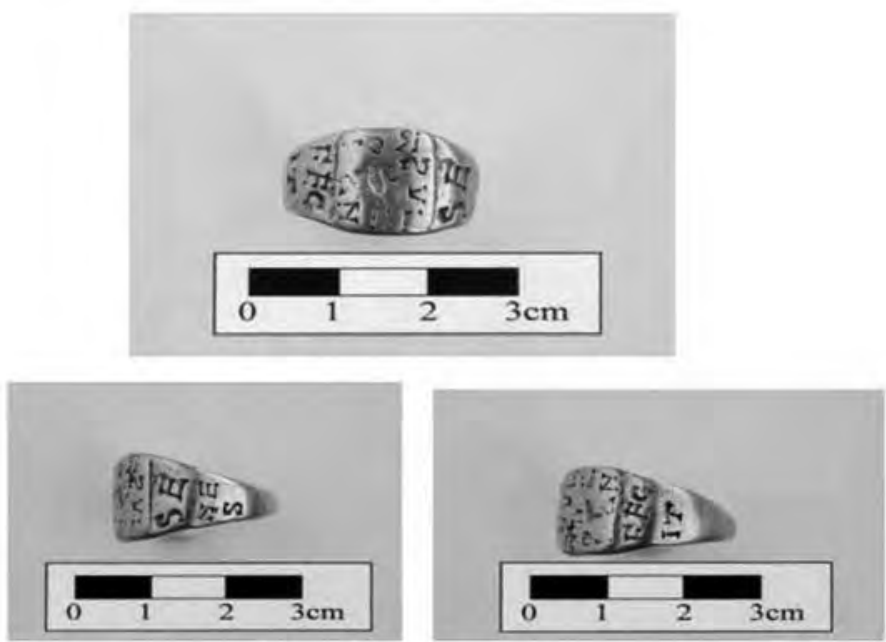

N. 20 - Lám. II, Fig. 7 (Inv. CE32563).

Oro. Fundido y cincelado. Diámetro: $21 \mathrm{~mm}$. Anch. $11 \mathrm{~mm}$. Peso: 7,33 g. Procedencia: Mérida. Necrópolis de San José. Ingresa en el Museo 4/10/85. Inscripción: Lateral: SE/NES Lateral: FE/CIT Chatón: IN/OR/SVI?? Datación: Siglo V-VII d. C

Comentario: Aro de sección semicircular, plano al interior, que se ensancha en el centro para formar chatón. Tiene inscripción a los lados del chatón (SE/NES y FE/CIT), así como en el mismo, en este caso de más difícil lectura (IN/OR/ SVI??). Esta última inscripción se sitúa en la perímetro del mismo, alrededor de una figura aviforme, resuelta de forma muy esquemática.

Nos encontramos ante una tipología habitual, de larga tradición romana y cuyo modelo se extiende a lo largo de toda la tardoantigüedad. Sin embargo, la excepcionalidad de la pieza radica en la cantidad de metal aurífero que emplea para su fabricación y, por tanto, el alto valor de la misma. De hecho, se conocen pocas piezas realizadas en oro adscritas a estos momentos procedentes del solar emeritense o de su inmediato territorio. A este respecto, destacamos, además de la pieza incluida en este estudio con el $\mathrm{n}^{\circ} 21$, el anillo procedente del Turuñuelo (Medellín, Badajoz), hoy en el MAN (n. ${ }^{\circ}$ inv. 1963/56/20), también fabricado en el metal aurífero, que formaba parte del ajuar de una rica dama datado a fines del siglo vi d.C. (Pérez Martín 1961: 13-14, Lám. 4, Fig. n.o 8). El anillo concretamente es un aro, plano al interior, que se ensancha en el centro para formar el chatón, que recibe la inscripción: NSII. 
Por otro lado, el lugar de hallazgo, la necrópolis cristiana de San José, así como la inscripción, el tipo de letra empleada en ella y la iconografía que presenta, son los elementos que permiten situarlo entre el siglo v-viI d.C., pero sin mayores precisiones.

La inscripción no ha podido ser leída en su totalidad. Por un lado, la correspondiente a los laterales del chatón no ofrece dificultad ni en su lectura ni en su interpretación: SENES FECIT, es decir, "lo hizo Senes". Sin embargo, la inscripción situada en el interior del chatón no ha podido ser leída con claridad. Proponemos la siguiente lectura: IN OR SVI ${ }^{4}$. Ésta se referiría a su ordenación como algún cargo eclesial y es que, recordemos, que tanto la iconografía como el metal noble con el que está fabricado nos remite a un poseedor relacionado con la alta jerarquía eclesiástica. Por otro lado, el tipo de letra empleada es la habitual para los epígrafes cristianos emeritenses de los siglo vi y viı d.C. (Ramírez Sádaba y Mateos Cruz 2000).

En cuanto a la iconografía, en la descripción se ha aludido a un aviforme, que protagoniza como elemento iconográfico el chatón. Creemos que se podría tratar de una paloma. En ocasiones es difícil distinguir, dado el esquematismo y la poca recreación en detalles anatómicos, la especie de animal. Sin embargo, teniendo en cuenta que las palomas y los pavos reales son las aves más representadas en la iconografía cristiana de estas fechas ${ }^{5}$ y que los últimos pueden ser identificados por la cresta o la larga cola, nos inclinamos a pensar en la paloma con motivo más plausible.

La paloma en la iconografía cristiana tendrá diferentes lecturas, pero su sola presencia es identificada como ideograma simbólico de Cristo. Sus distintas lecturas tienen que ver con el contexto narrativo en el que se inserta, desde la paz celeste e imagen del paraíso, en el ámbito funerario, o como motivo acompañando a jarrones de frutas, guirnaldas, crismón, etc. También con la rama de olivo en el pico, rememorando el episodio de Noé, con un significativo mensaje de Salvación. También su presencia en momentos como el Bautismo de Cristo representando el Espíritu Santo o en la propia Anunciación. Recogemos por tanto, sólo algunas de las advocaciones de la paloma en la simbología cristiana, que dan una idea de la importancia de la misma y por tanto justifican sobradamente su presencia en una pieza como la que analizamos.

Se conocen numerosos ejemplares de anillos visigodos en los que el chatón de conforma con una estructura similar a la analizada en este caso, es decir, aviforme en el centro, no siempre identificado como paloma, e inscripción alrededor de la

\footnotetext{
${ }^{4}$ Agradecemos al Prof. Ramírez Sádaba su ayuda y consejos para la lectura e interpretación de este epígrafe.

${ }^{5}$ REINHART, WM. 1947: 168. Alude a cómo uno de los tipos más habituales en el período visigodo serán los de chatón, que permiten desarrollar tanto inscripciones como grabar figuras, entre las cuales, señala como una de las más habituales las palomas.
} 
misma. Reinhart recoge varios de ellos en su trabajo (Reinhart 1947: 171-175, Fig. 1.6, 1.7, 1.8, 1.13 y 1.16). Con un ave sólo en el centro, identificada esta vez sí como paloma, es un anillo hallado en unas tumbas visigodas en el entorno del teatro romano de Córdoba (Moreno Almenara y González Vírseda 2005: 201-203, Lám. IX. Fig. 5). Otro adorno anular, procedente de "El Santiscal" (Arcos de la Frontera, Cádiz) presenta aviforme en el centro del chatón, rodeado de inscripción con el nombre del propietario, antecedido de cruz griega (Sánchez Sánchez 1990). En la orfebrería bizantina, también se conocen numerosos ejemplares que repiten este tema iconográfico (Baldini Lippolis 1999: 208-211).
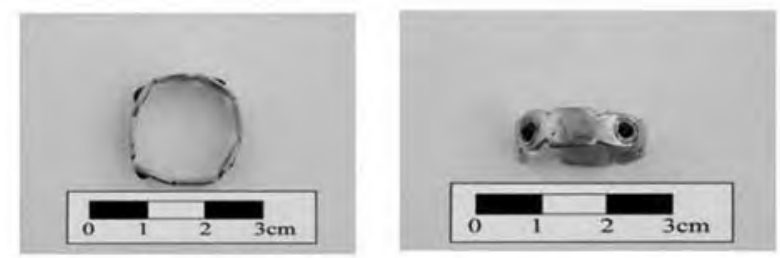

N.o 21 - Lám. III, Fig. 1 (Inv. CE37247).

Oro y granates. Fundido, embutido y cincelado. Diámetro: $19 \mathrm{~mm}$. Anch. 5 mm. Peso: 3.85 g. Procedencia: Mérida. Se incluía dentro de la Colección Quirós, comprada por la Junta de Calificación, Valoración y Exportación de Bienes Culturales para el MNAR en el 2001. Datación: Siglo V-VI d. C. Inscripción: DILI TV RI??

Comentario: Aro de ocho facetas, de sección semicircular plano al interior, que alterna en cada faceta incrustación de granates (cuatro) con inscripción grabada en tres de ellas, y crismón en la cuarta. El anillo fue publicado en el 2001 por. A. Castellanos, que sitúa su datación en el siglo iv d.C.

La presencia del crismón es el elemento que permite situar cronológicamente la pieza a partir del siglo Iv d.C., puesto que la inscripción, ilegible, no nos permite aventurar ningún tipo de fórmula. Éste elemento iconográfico es clave para situar el análisis de la pieza, destacando junto a la calidad de la misma y el uso del granate como recurso técnico decorativo. En cuanto al crismón, puede relacionarse con el anillo de Baena (Córdoba), de chatón destacado que presenta grabado crismón, junto con inscripción del nombre de la propietaria y advocación religiosa en el aro (Morena y Sánchez 2011).

La morfología de la pieza es singular, aro facetado en ocho lados. Sólo se conoce una tipología similar como son los anillos bizantinos utilizados en las ceremonias matrimoniales, que normalmente tenían forma octogonal como símbolo de la fertilidad (Papanokola-Bakirchí 2003: 145, n. ${ }^{\circ}$ 127). En este sentido, hay que recordar la más que presencia de población de procedencia oriental y de artesanos, más concretamente, en la antigua Augusta Emérita (De Hoz 2007; García Moreno 1972) así como la influencia de la plástica bizantina en la escultura visigoda emeritense (Cruz Villalón 1985). 
En el caso concreto de la orfebrería, los materiales de origen oriental en la ciudad de Mérida y su territorio es significativa, con conjuntos como el citado del Turuñuelo (Medellín, Badajoz) o los pendientes conservados actualmente en la Walters Art Museum ( ${ }^{\circ}$ inv. 57.560 y 57.561) y procedentes de Extremadura (Baldini Lippolis 1999: 98, n. ${ }^{\circ}$ 5, con bibliografía anterior). Todos estos conjuntos están fechados en el siglo vi d.C.

Además, pueden proponerse otras relaciones contextuales para esta pieza a la luz de nuevos hallazgos en el solar emeritense. Nos referimos a un magnífico ajuar hallado en el "Solar de Blanes" y sólo parcialmente publicado (Heras Mora 2006) A lo que sabemos está conformado por collar de cuentas esféricas y lanceoladas, en oro y granates, junto a la agujas de pelo. El conjunto puede adscribirse a los materiales hispano contextualizados dentro del llamado "horizonte póntico-danubiano-hispano" de la primera mitad del sigloV d.C. (López Quiroga 2010: 112-132). El empleo del oro y el granate, nada habitual en lo que conocemos de la orfebrería cristiana de Mérida es el elemento técnico que permite tal relación, aunque hay que admitir, que tanto el anillo como el conjunto de Blanes suponen un unicum en nuestro conocimiento actual de la joyería tardoantigua emeritense. En cualquier caso, la cronología del anillo debe ser adelantada, tal y como se propone en su ficha técnica, a los siglos v-vi d.C..

Bibliografía:CASTELLANOHERNÁNDEZ,M.A.2001:23,Lám.4.7y4.8.

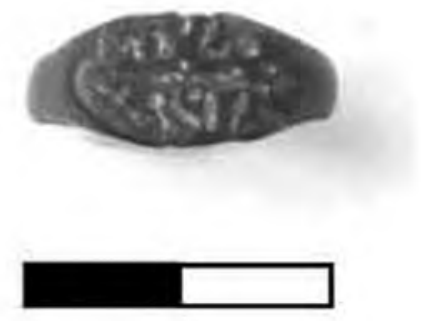

N.o 22 - Lám. III, Fig. 2.

Bronce. Fundido y cincelado. Diámetro: 23 mm. Peso: 3,2 g. Procedencia: Villa romana de Torre Águila (Barbaño, Badajoz). CATA 37TG. CAPA2. No 1570. 11-12-85. Inscripción: Ilegible. Datación: Siglo VI d. C.

Comentario: Aro de sección semicircular, plano al interior, que se ensancha y aplana en la parte central para formar chatón. Éste tiene grabada inscripción ilegible. Todos los anillos incluidos en este estudio procedentes de la Villa de Torre Águila aparecieron en la necrópolis correspondiente a III Fase de ocupación de la Villa, contexto datado en el siglo vi d.C. (Rodríguez Martín 1997) ${ }^{6}$.

\footnotetext{
${ }^{6}$ Agradecemosa Germán Rodríguezlasfacilidades de consulta de materialasícomo su ayuda y comentarios para situar el contexto de todos los materiales hallados en la Villa de Torre Águila.
} 
La tipología del anillo es propia del mundo tardoantiguo. Su construcción es simple, con delimitación del chatón que se ensancha para recibir inscripción. Posiblemente en este caso se trate del monograma del propietario.

N.o $23-$

Bronce. Fundido y cincelado. Diámetro: $20 \mathrm{~mm}$. Peso: 0,62 g.

Procedencia: Villa romana de Torre Águila (Barbaño, Badajoz). TA85. CATA 132. CAPA1. 24-12-85. Datación: Siglo VI d.C.

Comentario: Aro de sección plana, liso al interior y estriado al exterior. Esta morfología sencilla de aro estriado es un modelo ya presente en el mundo romano pero que continúa durante los siglos posteriores.

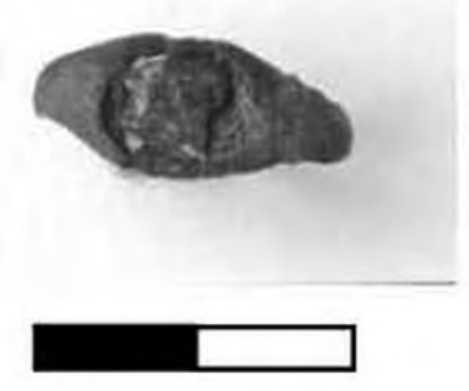

N. 24 - Lám. III, Fig. 3.

Bronce y pasta vítrea. Fundido y embutido. Diámetro: $19 \mathrm{~mm}$. Anch. chaton. 9 mm. gr. 2 mm. Peso: 1,41 g. Procedencia: Villa romana de Torre Águila (Barbaño, Badajoz). TA85. CATA 84. CAPA 3. n.o 2303. Datación: Siglo VI d.C.

Comentario: Aro laminar de sección plana, que se ensancha en el centro para formar chatón. Éste es de forma elíptica y hueco, donde se ha incrustado pasta vítrea, en parte perdida.

La tipología de anillos con chatón de incrustaciones vítreas es de larga tradición romana, y se constata su presencia y continuación en las necrópolis de la Antigüedad Tardía, especialmente hasta el siglo vi d.C. (Reinhart 1947: 168).

\section{N. ${ }^{\circ} 25-$}

Bronce. Fundido y cincelado. Diámetro: $19 \mathrm{~mm}$. Gr. $2 \mathrm{~mm}$. Peso: 0,69 g. Procedencia: Villa romana de Torre Águila (Barbaño, Badajoz). TA85. CATA 84. CAPA 3. n. ${ }^{\circ}$ 2303. Datación: Siglo VI d.C.

Comentario: Aro laminar de sección plana, que presenta en el exterior decoración grabada, con una línea incisa continua que recorre todo el perímetro de la pieza, cruzada por multitud de pequeñas líneas perpendiculares. 


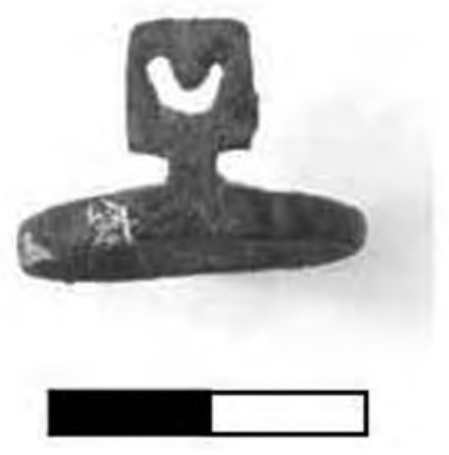

N. 26 - Lám. III, Fig. 4.

Bronce. Fundido y cincelado. Diámetro: $21 \mathrm{~mm}$. gr. $2 \mathrm{~mm}$. Peso: 1,72 g.; Apéndice: Long. $11 \mathrm{~mm}$. anch. $9 \mathrm{~mm}$. Procedencia/Historia del objeto: Villa romana de Torre Águila (Barbaño, Badajoz). Datación: Siglo VI d.C.

Comentario: Aro de sección semicircular, plano al interior, que presenta en el centro un apéndice cuadrangular sobre base mas estrecha, que en su interior está calado en forma acorazonada. Se trata de un tipo conocido como anillo-llave, habitual en contextos de los siglos in y in d.C. Eran utilizados tanto por mujeres como por hombres para llevar consigo la llave que habría cofrecillos con joyas y secretos de tocador, las primeras, o cajas fuertes con documentos, los segundos. La morfología de este tipo es variada y se conocen ejemplares similares a la pieza de Torre Águila (Bagot et al. 2012: 203-204, no 536 y 538). En Hispania no son numerosos los ejemplares conocidos y publicados, destacando el ejemplar procedente de la Villa romana de la Morlaca (Villamediana, La Rioja) (Castillo 1998) y el procedente del solar de la Morería de Sagunto (López y Delaporte 2005: 151, n. $\left.{ }^{\circ} 21\right)$, ambos datados en el siglo iII d.C.

\section{Conclusiones}

Visto el catálogo razonado de materiales, no cabe duda de la existencia de una comunidad cristiana en la ciudad de Mérida que vive su fe y que ésta queda reflejada en el empleo de ciertos elementos simbólicos en los adornos personales que les acompañan. Sin embargo, cierto es que la lectura es sutil, y hay que hacer un análisis detallado de toda la información relativa en cado uno de estos adornos anulares.

En el caso de aquellos materiales procedentes de contextos arqueológicos datados, su adscripción no tiene dudas, a pesar de que, de manera paradójica, estos, tanto los procedentes de la Basílica de Casa Herrera como de la necrópolis de la Villa de Torre Águila, no ofrezcan ningún otro elemento para su adscripción cronocultural. 
En el caso de los materiales procedente de la Basílica de Casa Herrera, se trata de un conjunto de 7 anillos procedentes de distintos enterramientos en los alrededores de la Basílica, situada a $7 \mathrm{~km}$. de Mérida. El edificio fue descubierto en 1943, a raíz de unos hallazgos casuales, por José Serra Rafols, realizando una primera campaña de excavación ese mismo año. En 1972 y 1973 se retomaron los trabajos en la zona por parte de Thilo Ulbert y Luis Caballero Zoreda, que fechan la basílica en torno al 500 d.C. y tanto en su interior como en los alrededores fueron excavados enterramientos hasta un total de 59. Sin embargo, pocas de ellas ofrecieron ajuares metálicos, sólo 6, que se reducen a este grupo citado de 7 anillos.

Las piezas incluidas en este catálogo procedentes de la Villa de Torre Águila, en su práctica totalidad fueron halladas en la zona de necrópolis de la Villa correspondiente a lo que su excavador, F. German Rodríguez, denomina III Fase de ocupación, fechada en el siglo vi d.C.

En cuanto a las conclusiones plausibles que pueden extraerse del análisis de la colección de anillos tardoantiguos del MNAR son, en primer lugar, la corroboración de la difusión y amplia aceptación por parte de la población de este tipo de adorno personal, que ya en su momento advertía Reinhart. Uno de los motivos de su mayor difusión y su empleo por amplios espectros de la sociedad, comparado con época romana, quizá sea el abundante empleo del bronce de baja calidad, lo que hacía su coste más bajo y por tanto más accesible a la población. Se observa cómo la utilización de los materiales más nobles, tales como el oro, queda reservado para piezas muy destacadas, que por su calidad técnica e iconografía debieron pertenecer muy posiblemente a personajes de alto rango social, con acceso a este tipo de piezas.

Con respecto a las tipologías, se aprecia una continuación de los tipos romanos, sin aportar novedades, aunque decantándose por aquellos de sencilla fabricación: laminares o filiformes. Destaca sin duda el empleo del chatón como campo de expresión singular de la individualidad, bien a través de la propia identificación del poseedor, bien a través de la proclamación de su fe a partir de elementos iconográficos cristológicos, como la cruz simple, bien a través de iconografías más complejas. 


\section{BibLIOgRAFía}

ÁlVAREZ MARTÍNEZ, J. M.; MATEOS CRUZ, P. (Eds.) (2010) Mérida. 2000 años de Historia, 100 años de Arqueología. Mérida.

BAGOT, Jaume, at al. (2012) El legado de Hefesto. Barcelona.

BALDINI LIPPOLIS, I. (1999) L'Oreficeria nelll'Imperio di Costantinopoli tra IV e VII secolo. Bari.

BISCONTI, Fabrizio (2000) Temi di iconografia paleocristiana. Roma (Sussidi allo Studio delle Antichitá Christiane 13).

CABALLERO, L.; ULBERT, T. (1976) La Basílica Paleocristiana de Casa Herrera en las cercanías de Mérida (Badajoz). Madrid.

CANTILLO VÁZQUEZ, M. A. et al. (2007) - Intervención arqueológica realizada durante las obras de la A-66 (variante Mérida-Autovía de la Plata). Mérida. Excavaciones Arqueológicas. Memoria 10, p. 77-89.

CASTILLO PASCUAL, M. J. (1998) Un ejemplar de anillo-llave procedente de la Villa romana de la Morlaca (Villamediana, La Rioja). IBERLA, 1, p. 207-211.

CRUZ VILLALÓN, M. (1985) - Mérida Visigoda. La Escultura Arquitectónica y Litúrgica, Badajoz.

DE HOZ, M. P. (2007) - Las inscripciones griegas como testimonio de la presencia de orientales en la Mérida visigoda, en Munus quaesitum meritis. Homenaje a Carmen Codoñer. Salamanca, p. 481-489.

GÓMEZ MORENO, M. (1888) Medina Elvira, Facsímile 1986, Granada.

GONZÁLEZ FERNÁNDEZ,J. (2002) La epigrafía visigoda: Tradición y originalidad. In: González (Ed.) San Isidoro. Doctor Hispaniae, Sevilla, p. 35-50.

HERAS MORA,J. (2006) Un collar de oro y granates de época visigoda. Revista Foro, 43, p. 6.

LÓPEZ BRAVO, F.; DELAPORTE, S. (2005) Estudio preliminar del mobiliario metálico de época romana del Solar de la Morería de Sagunto. ARSE 39, p. 145-182.

LÓPEZ QUIROGA, J. (2010) - Arqueología del mundo funerario en la Peninsula Ibérica (siglos $V$-X). Madrid (Colección Biblioteca Básica 3).

MADRID BALANZA, M. J.; VIZCAÍNO SÁNCHEZ, J. (2006) Nuevos elementos de ajuar de la necrópolis oriental de Carthago Spartaria (I). Mastia, 5, p. 85-130. 
MARTÍNEZ SANTA-OLALLA, J. (1933) Excavaciones en la necrópolis visigoda de Herrera del Pisuerga (Palencia). Memoria de los Trabajos realizados en dichas excavaciones. Madrid.

MELIDA ALINARI, J. R. (1925) Catálogo monumental de España. Provincia de Badajoz: 1907-1910. Madrid.

MEZQUIRIZ IRUJO, M.Á. (1965) Necrópolis visigoda de Pamplona. Príncipe de Viana, Año XXVI, n. o 98-99, p. 107-131.

MOLINERO PÉREZ, Antonio (1971) Aportaciones de las excavaciones y hallazgos casuales (1941-1959) al Museo Arqueológico de Segovia. Excavaciones Arqueológicas en España 72.

MORENA, J. A.; SÁNCHEZ, I. (2011) Un anillo de oro con inscripción del Museo Histórico de Baena (Córdoba). Pyrenae, n. ${ }^{\circ} 42$ (1), p. 129-142.

MORENO ALMENARA, M.; GONZÁLEZ VÍRSEDA, M. L. (2005) Dos tumbas hispanovisigodas del teatro de la Axerquía de Córdoba. Anales de Arqueología Cordobesa n. ${ }^{\circ}$ 16, p. 193-206.

MORÍN DE PABLOS, J.; BARROSO CABRERA, R. (2010) El mundo funerario. De las necrópolis tardorromanas a los cementerios hispanovisigodos en el oeste peninsular. In: Morín de Pablos et al. (Coord.) El tiempo de los Bárbaros: Pervivencia y transformación en Galia e Hispania (SS. V-VI d.C.), Zona Arqueológica 11, p. 149-180.

MUÑIZ JAÉN, I.; BRAVO CARRASCO, A. (2000) La Toreútica en las necrópolis tardorromana y de época visigoda de El Ruedo (Almedinilla, Córdoba). Antiquitas 11-12, p. 189-198.

NAVASCUÉS y DE JUAN, J. M. (1948) - Los epígrafes cristianos latinos de Mérida. Tesis doctoral mecanografiada.

ORTIZ ALESÓN, M.; BLASCO RODRIGUEZ, F. (1985) Avance de estudio del ajuar de uso personal de la necrópolis del Caballar(Usagre, Badajoz).Excavcaiones Arqueológicas en España. Homenaje a D. Jesús Cánovas, p. 161-170.

PAPANIKOLA-BAKIRCHÍ, D. (2003) Matrimonio, maternidad e Hijos. In: Papanikola-Bakirchí; Albani (Dir.) Aspectos de la vida cotidiana en Bizancio, p. 145-149.

PÉREZ MAESTRO, C. (2005) Nuevas aportaciones para el conocimiento de la secuencia ocupacional del área periurbana de Mérida. Mérida. Excavaciones Arqueológicas 8, p. 227-245.

PÉREZ MARTÍN, María José (1961) Una tumba hispano-visigoda excepcional hallada en el Turuñuelo. Medellin (Badajoz), Trabajos de Prehistoria Vol. IV. 
RAMÍREZ SÁDABA, J. L.; MATEOS CRUZ, P. (2000) Catálogo de las Inscripciones cristianas de Mérida, Cuadernos Emeritenses 16.

REINHART, W. M. (1947) Los anillos hispano-visigodos. Archivo Español de Arqueologia, T. XX, p. 167-178.

RIPOLL LÓPEZ, G. (1998) Toréutica de la Bética (siglos VIy VII d.C.). Barcelona.

RODRÍGUEZ MARTÍN, F. G. (1997) La Villa romana de Torre Águila (Barbaño, Badajoz) a partir del siglo IV d.C. Consideraciones generales. En Congreso Internacional La Hispania de Teodosio, Vol. II, p. 697-711.

SÁNCHEZ SÁNCHEZ, J. M. (1990) Un anillo inédito con inscripción procedente de "El Santiscal"(Arcos de la Frontera, Cádiz). Habis, 21, p. 229-233.

ICERV = VIVES, J. (1969) Inscripciones cristiana de la España romana y visigoda. Barcelona

ZEISS, H. (1934) Die Grabfunde aus dem Spanischen Westgoten-Reinch. Berlin. 